\title{
Primary left ventricular rehabilitation is effective in maintaining two-ventricle physiology in the borderline left heart
}

\author{
Sitaram M. Emani, MD, Emile A. Bacha, MD, Doff B. McElhinney, MD, MPH, Gerald R. Marx, MD, \\ Wayne Tworetzky, MD, Frank A. Pigula, MD, and Pedro J. del Nido, MD
}

Objective: Borderline left heart disease is characterized by left heart obstructive lesions (coarctation, aortic and mitral stenoses, left ventricular hypoplasia) and endocardial fibroelastosis. The multilevel obstruction and impaired left ventricular systolic and diastolic function contribute to failure of biventricular circulation. We studied the effects of left ventricular rehabilitation — endocardial fibroelastosis resection with mitral or aortic valvuloplasty—on left ventricular function and clinical outcomes.

\begin{abstract}
Methods: All patients with borderline left heart structures and endocardial fibroelastosis who underwent a primary left ventricular rehabilitation procedure were retrospectively analyzed to determine operative mortality, reintervention rates, and hemodynamic status. Left heart dimensions and hemodynamics were recorded from preoperative and postoperative echocardiogram and cardiac catheterization. Postoperative left atrial pressure was obtained from the intracardiac line early after left ventricular rehabilitation. Preoperative and postoperative values were compared by paired $t$ test.
\end{abstract}

Results: Between 1999 and 2008, 9 patients with endocardial fibroelastosis and borderline left heart disease underwent left ventricular rehabilitation at a median age of 5.6 months (range, 1-38 months). There was no operative mortality, and at a median follow-up of 25 months (6 months to 10 years) there was 1 death from noncardiac causes and 2 patients required reoperations. Significant increases in ejection fraction and left ventricular end-diastolic volume were observed, whereas left atrial pressure and right ventricular/left ventricular pressure ratios decreased postoperatively.

Conclusion: In patients with borderline left hearts, primary left ventricular rehabilitation with endocardial fibroelastosis resection and mitral and aortic valvuloplasty results in improved left ventricular systolic and diastolic performance and decreased right ventricular pressures. This approach may provide an alternative to singleventricle management in this difficult patient group. (J Thorac Cardiovasc Surg 2009;138:1276-82)

Earn CME credits at

http://cme.ctsnetjournals.org

Hypoplastic left heart disease occurs as a spectrum, with variable hypoplasia of 1 or more left-sided structures and ventricular dysfunction. Patients with more severe disease are managed with univentricular palliation or transplant, whereas patients at the milder end of the spectrum (eg, neonatal aortic stenosis with normal left ventricular [LV] size and mild mitral hypoplasia) undergo attempts at biventricular repair. Despite a number of studies investigating factors predictive of successful biventricular management, there is a population of patients with moderate hypoplastic left heart disease in whom it is difficult to determine whether a biventricular circulation is sustainable. ${ }^{1-3}$ Such patients are often referred to as having

From the Children's Hospital Boston, Boston, Mass.

Received for publication May 1, 2009; revisions received July 26, 2009; accepted for publication Aug 9, 2009; available ahead of print Oct 13, 2009.

Address for reprints: Pedro J. del Nido, MD, Children's Hospital Boston, 300 Longwood Avenue, Boston, MA 02115 (E-mail: pedro.delnido@cardio.chboston.org). $0022-5223 / \$ 36.00$

Copyright (c) 2009 by The American Association for Thoracic Surgery doi:10.1016/j.jtcvs.2009.08.009 a borderline left heart disease. Infants with borderline hypoplastic left heart structures present a unique challenge to the clinician. The constellation of aortic and mitral valve stenosis, small LV cavity volume, and ventricular restriction due to the presence of endocardial fibroelastosis (EFE) impedes biventricular repair. Treatment of patients with an extremely small $\mathrm{LV}$ is single-ventricle palliation, whereas treatment of borderline left heart disease is dichotomous: single-ventricle palliation or biventricular repair. Interventions commonly performed to promote initial biventricular circulation consist of relief of inflow and outflow tract obstructions by catheter or surgical maneuvers. ${ }^{4,5}$ However, the presence of EFE, which impedes both systolic and diastolic myocardial function, is a risk factor for biventricular repair and may necessitate eventual pursuit of single-ventricle palliation. ${ }^{3}$

A surgical strategy consisting of primary relief of LV inflow and outflow tract obstruction by aortic and mitral valvuloplasty, coarctation repair, and resection of EFE has been applied to a subgroup of patients with borderline hypoplastic left heart structures and EFE. The goal of this strategy, which we have referred to as primary LV rehabilitation, is to recruit the left heart into a biventricular circulation. Since 1999, we have used the LV rehabilitation strategy in select patients with 


\section{Abbreviations and Acronyms \\ ASD $=$ atrial septal defect \\ $\mathrm{EFE} \quad=$ endocardial fibroelastosis \\ $\mathrm{LV}=$ left ventricular \\ LVOT = left ventricular outflow tract \\ MRI = magnetic resonance imaging \\ UVR-SA = Univentricular Survival Advantage}

borderline hypoplastic left heart structures. The primary goal of this study is to report the clinical outcomes of the LV rehabilitation strategy.

\section{MATERIAL AND METHODS \\ Study Design}

All infants who underwent primary LV rehabilitation at Children's Hospital Boston between 1999 and 2008 were reviewed. Primary LV rehabilitation refers to mitral valvuloplasty, relief of left ventricular outflow tract (LVOT) obstruction, and EFE resection as a means of maintaining biventricular circulation. Left heart structures were termed "borderline" hypoplastic if the dimension $\mathrm{Z}$ score was less than -2.0. Patients were selected for this strategy if they demonstrated borderline hypoplasia of 1 or more left heart structures, LV EFE, and clinical deterioration despite initial attempts at maintaining biventricular circulation. Most patients had critical aortic valve stenosis and coarctation, and had required catheter-based balloon dilation of the aortic valve or surgical coarctation repair, but demonstrated systolic and diastolic ventricular dysfunction despite these interventions. Clinical deterioration in these patients was associated with elevated left-sided filling pressures on cardiac catheterization. Patients were excluded if they had aortic or mitral atresia, ventricular septal defect, heterotaxy syndrome, or atrioventricular or ventriculoarterial discordance. The study was approved by the Children's Hospital Boston Institutional Review Board. Interventions performed before LV rehabilitation (fetal or postnatal balloon dilation of the aortic valve, surgical coarctation repair), details of the operative procedure, and reinterventions after LV rehabilitation were recorded from hospital records. Echocardiographic data and hemodynamic measurements from cardiac catheterization were recorded preoperatively and postoperatively. The Univentricular Survival Advantage (UVR-SA) prediction tool, a regression model that calculates the predicted survival advantage of single-ventricle repair over biventricular repair in critical LVOT obstruction, was determined from the online calculator available on the Congenital Heart Surgeons' Society website (www.chss.org). The primary outcome measures of this study were survival, hemodynamics, and sizes of left heart structures.

\section{Left Ventricle Rehabilitation Procedure}

The primary LV rehabilitation strategy used a combination of techniques to relieve inflow and outflow tract obstruction and resect EFE. The procedure was performed through a median sternotomy with cardiopulmonary bypass and moderate hypothermia. The mitral valve was approached transeptally and inspected to determine the mechanisms of mitral stenosis or regurgitation. Commonly used techniques to relieve inflow obstruction include division of secondary or accessory chordae, separation (splitting) of fused papillary muscles and abnormal attachments of papillary muscles to septum or LV free wall, chordal elongation, commissurotomy, and débridement of thickened leaflet tissue. EFE resection involved removal of this noncompliant endocardial material by sharp dissection, with a surgical scalpel or tenotomy scissors. Resection was performed through the mitral valve orifice or the LVOT.

The mechanisms of aortic stenosis or regurgitation were assessed by preoperative echocardiogram or magnetic resonance imaging (MRI) and intraoperative inspection. Techniques used for obstruction at the valvar level included commissurotomy, débridement of thickened aortic valve leaflets, and augmentation of deficient leaflets with pericardium. When subvalvar obstruction was present, resection of the subvalvar membrane, muscle bar, or accessory chordae between mitral valve and LVOT was performed. Fenestrated closure of the atrial septal defect (ASD) was performed by partial primary reapproximation of the rim of the ASD or by fenestrated pericardial patch closure ( $4 \mathrm{~mm}$ fenestration) as a means of allowing decompression of the LV. The duration of cardiopulmonary bypass, crossclamp, and fibrillatory arrest were recorded.

\section{Hospital Course}

The intensive care unit and hospital lengths of stay, duration of mechanical ventilation, and duration of inotropic support were recorded. The left atrial pressure, measured by the surgically placed intracardiac line placed at the time of surgery, was recorded before removal of the line.

\section{Echocardiographic, Magnetic Resonance Imaging, and Hemodynamic Measurements}

All echocardiograms were reviewed by an independent reviewer to determine the ejection fraction, LV mass-to-volume ratio, and dimensions of left heart structures before and after primary LV rehabilitation. On MRI, EFE manifested at the endocardial surface as a rim of hyperintense signal in the myocardial delayed-enhancement sequences (Figure 1). The degree of EFE was graded according to previously published methodology ( $0=$ none; $1=$ involvement of papillary muscles only; $2=$ papillary muscle with some endocardial surface involvement; $3=$ extensive endocardial surface involvement). The sizes of left heart structures were recorded from echocardiograms obtained postnatally, before surgical intervention, and at most recent follow-up. All dimensional measurements were compared with normative plot according to body surface area and expressed as a Z-score value. Right ventricular pressure was estimated from the velocity of the tricuspid regurgitation jet (when present) and used as a surrogate for pulmonary arterial pressures. Hemodynamic data (left atrial, LV enddiastolic, and right ventricular pressures) were obtained from cardiac catheterization performed before and after $\mathrm{LV}$ rehabilitation.

\section{Statistical Analysis}

Comparison of preoperative and postoperative LV dimensions and hemodynamics were analyzed by paired $t$ test. Descriptive data are expressed as mean ( \pm standard deviation) or median (range).

\section{RESULTS \\ Patient Characteristics}

Between January 1999 and December 2008, 9 patients (3 female) with borderline left heart and EFE underwent primary LV rehabilitation as a means of maintaining biventricular circulation. Attempts to maintain biventricular circulation before LV rehabilitation included postnatal balloon dilation of the aortic valve $(n=7)$ and coarctation repair $(n=3)$. Prenatal balloon dilation of the aortic valve was performed in 5 patients (Table 1). None were dependent on prostaglandin infusion beyond the neonatal period. In all patients, the indication for surgical evaluation was development of symptoms of congestive heart failure and evidence of left atrial hypertension. Dimensions of left heart structures and hemodynamics measured on the preoperative echocardiogram and cardiac catheterization are shown in Table 2. Eight patients had grade $3 \mathrm{EFE}$, and 1 patient had grade 2 


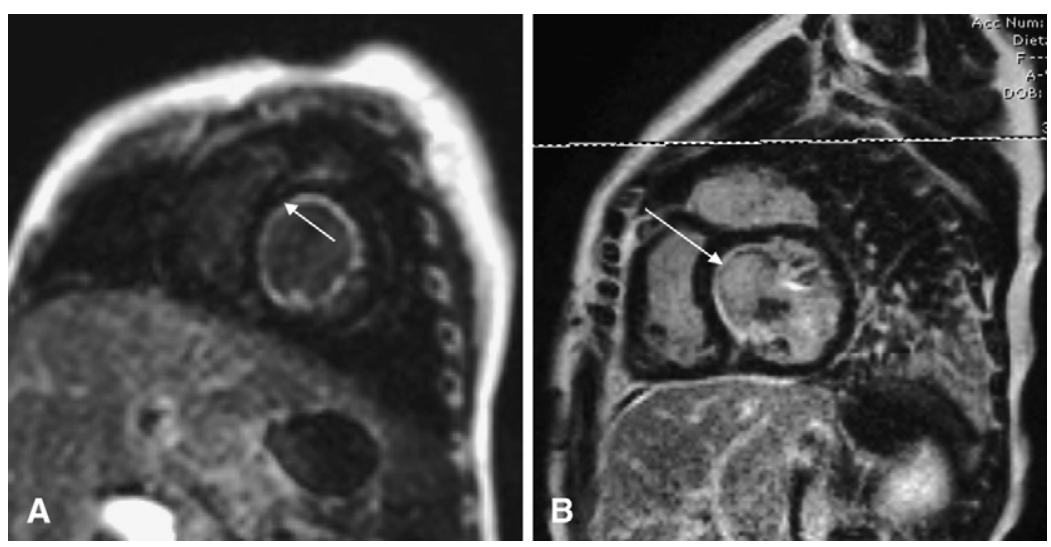

FIGURE 1. MRI images depicting circumferential EFE before LV rehabilitation (A) and residual EFE along the interventricular septum on follow-up MRI (B).

EFE. The median UVR-SA score for all patients was 6.1 (range, -15.5 to 23.6). Six of the 9 patients had positive values for the UVR-SA score, suggesting survival benefit for single-ventricle palliation over biventricular repair in these patients.

\section{Operative Procedure}

Median age at operation was 5.6 months (19 days to 3 years). Details of the primary LV rehabilitation procedure are provided in Table 3. Mitral valvuloplasty and EFE resection were performed in all patients, whereas LVOT procedures were performed in 6 patients. Mitral valvuloplasty entailed separation of fused papillary muscles in all 9 pa- tients, thinning of thickened leaflets in 5 patients, division of accessory or secondary chordae in 7 patients, and commissurotomy in 3 patients. Median durations of cardiopulmonary bypass, fibrillatory arrest, and crossclamp times are shown in Table 3. Seven patients had a period of fibrillatory arrest to allow examination of intracardiac structures before application of the crossclamp.

\section{Hospital Course}

Inotropic support with dopamine (3-10 $\mu \mathrm{g} / \mathrm{kg} / \mathrm{min})$ was maintained in all patients for a median of 4 days (1-12 days). The median duration of mechanical ventilatory support was 7 days (9 hours to 22 days). Eight patients required

TABLE 1. Preoperative echocardiographic and hemodynamic characteristics

\begin{tabular}{|c|c|c|c|c|}
\hline & Preoperative interventions & $\begin{array}{c}\text { Age at LV } \\
\text { rehabilitation (mo) }\end{array}$ & Details of $\mathrm{LV}$ rehabilitation & Reintervention \\
\hline 1 & Fetal balloon dilation & 4 & Mitral valvuloplasty, EFE resection & None \\
\hline 2 & $\begin{array}{l}\text { Postnatal balloon dilation of aortic valve, } \\
\text { coarctation repair through thoracotomy }\end{array}$ & 21 & Mitral valvuloplasty, EFE resection & None \\
\hline 3 & $\begin{array}{l}\text { Left thoracotomy for coarctation repair, } \\
\text { postnatal balloon dilation of aortic and } \\
\text { mitral valves }\end{array}$ & 7 & Mitral valvuloplasty, EFE resection & $\begin{array}{l}2 \text { reoperations for } \\
\text { mitral replacement }\end{array}$ \\
\hline 4 & Postnatal balloon dilation of aortic valve & 38 & $\begin{array}{l}\text { Mitral valvuloplasty, EFE resection, aortic } \\
\text { valvuloplasty }\end{array}$ & None \\
\hline 5 & Left thoracotomy for coarctation repair & 12 & $\begin{array}{l}\text { Mitral valvuloplasty, EFE resection, resection } \\
\text { of subaortic obstruction }\end{array}$ & None \\
\hline 6 & $\begin{array}{l}\text { Fetal and postnatal balloon dilations of aortic } \\
\text { valve }\end{array}$ & 1 & $\begin{array}{c}\text { Mitral valvuloplasty, EFE resection, aortic } \\
\text { valvuloplasty, fenestrated ASD closure }\end{array}$ & $\begin{array}{l}\text { Aortic and mitral } \\
\text { repair }\end{array}$ \\
\hline 7 & $\begin{array}{l}\text { Fetal and postnatal balloon dilations of aortic } \\
\text { valve }\end{array}$ & 2 & $\begin{array}{l}\text { Mitral valvuloplasty, EFE resection, aortic } \\
\text { valvuloplasty }\end{array}$ & None \\
\hline 8 & $\begin{array}{l}\text { Fetal and postnatal balloon dilations of aortic } \\
\text { valve }\end{array}$ & 1 & $\begin{array}{l}\text { Mitral valvuloplasty, EFE resection, resection } \\
\text { of subaortic obstruction, fenestrated ASD } \\
\text { closure }\end{array}$ & None \\
\hline 9 & $\begin{array}{l}\text { Fetal and postnatal balloon dilations of aortic } \\
\text { valve, left thoracotomy for coarctation } \\
\text { repair }\end{array}$ & 6 & $\begin{array}{l}\text { Mitral valvuloplasty, EFE resection, aortic } \\
\text { valvuloplasty, fenestrated ASD closure }\end{array}$ & None \\
\hline
\end{tabular}

$L V$, Left ventricle; $E F E$, endocardial fibroelastosis; $A S D$, atrial septal defect. 
TABLE 2. Preoperative echocardiographic and hemodynamic characteristics

\begin{tabular}{lc}
\hline Echocardiogram derived & \\
LV end-diastolic volume Z score & $-0.18 \pm 0.03$ \\
Aortic valve Z score & $-1.6 \pm 0.4$ \\
Mitral valve Z score & $0.5 \pm 0.6$ \\
Cardiac catheterization derived & \\
LV end-diastolic pressure (mm Hg) & $22 \pm 2.4$ \\
Left atrial pressure (mm Hg) & $28 \pm 6.3$ \\
Right ventricular pressure $(\mathrm{mm} \mathrm{Hg})$ & $70 \pm 18$ \\
\hline$L V$, Left ventricle.
\end{tabular}

milrinone for a median of 5 days (3-7 days), and 3 patients required additional inotropic support with epinephrine. Temporary dual-chamber pacing was required in 1 patient who developed transient second-degree heart block postoperatively. Postoperative intensive care unit and hospital length of stays were 17 days (1-45 days) and 27 days (5-64 days), respectively.

\section{Clinical Outcomes}

At median follow-up of 25 months (6 months to 10 years), there was 1 death $(11 \%)$ due to noncardiac causes (motor vehicle accident). Two patients underwent reinterventions. One patient had mitral valve replacement for severe mitral regurgitation and subsequent re-replacement because of development of thrombosis of the mechanical prosthesis. Another patient underwent surgical reintervention for aortic and mitral valve repair. Three of 9 patients had evidence of recurrent or persistent EFE on the interventricular septal surface of the LV on echocardiogram or MRI (Figure 1). Three patients had a right bundle branch block or hemifascicular block with mild prolongation of the QRS complex on electrocardiography, but none have required permanent pacing. Aortic regurgitation was moderate in 1 patient and mild or none in the remaining patients.

\section{Left Heart Dimensions and Hemodynamics at Postoperative Follow-up}

Postoperative left atrial pressures measured by the intracardiac catheter placed during the operation were recorded. The median left atrium pressure before removal of the catheter was $11 \pm 2.4 \mathrm{~mm} \mathrm{Hg}$, significantly lower than at preoperative catheterization (Table 4). Left heart dimensions and estimated right ventricular pressure on the most recent echocardiogram were compared with preoperative values, as summarized in Table 4. Postoperative cardiac catheterization was performed in 5 patients at a median of 4 months after surgery. The mean left atrial and LV end-diastolic pressures in these 5 patients were $16 \pm 1.1 \mathrm{~mm} \mathrm{Hg}$ and $12 \pm 2$ $\mathrm{mm} \mathrm{Hg}$, respectively, which were significantly lower than preoperative pressures measured at cardiac catheterization $(P<.05)$.
TABLE 3. Techniques using during left ventricle rehabilitation procedures

\begin{tabular}{lr}
\hline MV repair & $\mathrm{N}=9$ \\
EFE resection & $\mathrm{N}=9$ \\
Aortic valve repair & $\mathrm{N}=4$ \\
Subaortic resection & $\mathrm{N}=2$ \\
Fenestrated ASD closure & $\mathrm{N}=3$ \\
Total pump time (min) & $106 \pm 6$ \\
Aortic crossclamp time (min) & $59 \pm 7$ \\
Fibrillatory arrest time (min) & $19 \pm 4$ \\
\hline$M V$, Mitral valve; $E F E$, endocardial fibroelastosis; $A S D$, atrial septal defect.
\end{tabular}

\section{DISCUSSION}

This retrospective study reports our early experience with primary LV rehabilitation for elimination of LV inflow and outflow tract obstructions and resection of EFE in a group of patients with borderline hypoplastic left heart who were considered to be failing biventricular physiology. The LV rehabilitation procedure was associated with low operative mortality, immediate improvement in left atrial and right ventricular pressures, and maintenance of biventricular circulation at mid-term follow-up.

Risk factors that have been associated with poor outcome (death or conversion to single ventricle palliation) after biventricular repair include the size and multiplicity of the left-sided obstructive lesions and the presence of EFE. ${ }^{2,3,6}$ Higher grade of EFE (moderate or severe) has been shown to be a strong predictor of mortality after biventricular repair. $^{6-8}$ The poor prognosis in patients with circumferential EFE may be due to impairment of both systolic and diastolic ventricular performance. ${ }^{9}$ Previous reports of biventricular repair in patients with borderline hypoplastic left heart disease have demonstrated the importance of relieving inflow and outflow tract obstructions, but have not addressed the EFE that contributes to both diastolic and systolic

TABLE 4. Comparison of preoperative and postoperative echocardiographic and hemodynamic parameters

\begin{tabular}{|c|c|c|c|}
\hline & Preoperative & Recent follow-up & $P$ value \\
\hline \multicolumn{4}{|l|}{ Echocardiogram } \\
\hline Ejection fraction $(\%)$ & $36 \pm 12$ & $58 \pm 10$ & $<.01$ \\
\hline LVEDV Z score & $-0.2 \pm 1.7$ & $2.7 \pm 1.8$ & $<.05$ \\
\hline LV mass $\mathrm{Z}$ score & $0.63 \pm 2.2$ & $2.5 \pm 0.39$ & .04 \\
\hline $\begin{array}{l}\text { LV mass:volume ratio } \\
\quad \mathrm{Z} \text { score }\end{array}$ & $0.6 \pm 1.2$ & $0.9 \pm 2.1$ & NS \\
\hline $\begin{array}{l}\text { Aortic valve gradient } \\
\qquad(\mathrm{mm} \mathrm{Hg})\end{array}$ & $39 \pm 22$ & $28 \pm 19$ & NS \\
\hline $\begin{array}{l}\text { Mitral valve gradient } \\
\qquad(\mathrm{mm} \mathrm{Hg})\end{array}$ & $7 \pm 3$ & $5 \pm 2$ & NS \\
\hline $\begin{array}{l}\mathrm{RV}: \mathrm{LV} \text { systolic } \\
\text { pressure ratio }\end{array}$ & $0.78 \pm 0.36$ & $0.32 \pm 0.11$ & $<.05$ \\
\hline \multicolumn{4}{|c|}{ Cardiac catheterization or intracardiac line } \\
\hline LA pressure $(\mathrm{mm} \mathrm{Hg})$ & $28 \pm 6.3$ & $11 \pm 2.4^{\mathrm{a}}$ & $<.01$ \\
\hline
\end{tabular}


dysfunction of the LV. ${ }^{5,10}$ Hanley and colleagues successfully performed EFE resection combined with the RossKonno procedure in a group of patients with borderline left heart disease and observed increase in LV cavity volume with this procedure (personal communication). However, there have been no published reports describing the efficacy or intermediate-term results of EFE resection.

Candidates for primary LV rehabilitation include patients with borderline left heart structures and severe EFE who have failed attempts at biventricular repair or are considered high risk for biventricular repair because of elevated LV end-diastolic pressure and pulmonary hypertension. Most of the patients in this series underwent catheter-based intervention on the aortic valve or coarctation repair in the newborn period in attempts to maintain a biventricular circulation, thus permitting delay of LV rehabilitation until several months of age; only 2 patients had repair before 1 month of age. LV rehabilitation during the neonatal period can be challenging because of the difficulty of EFE resection and mitral valve repair through a small mitral valve orifice. Thus, LV rehabilitation procedure must be incorporated into a management strategy consisting of catheter-based intervention and relief of LVOT obstruction to allow optimal timing of repair.

Ejection fraction and left atrial pressure were measured as crude surrogates for systolic and diastolic LV performance. Although ejection fraction improved in patients undergoing $\mathrm{LV}$ rehabilitation, it was unclear whether this improvement was secondary to relief of LVOT obstruction, resection of EFE, or alteration in loading conditions. Significant impairment of systolic function is associated with severe circumferential EFE, and its removal may have contributed to the improved ejection fraction. Left atrial pressure was significantly reduced after LV rehabilitation; however, this pressure is affected by multiple factors, including intravascular volume, mitral valve stenosis or regurgitation, and ventricular compliance. More sensitive measures of systolic and diastolic function are required to accurately characterize changes in ventricular performance after LV rehabilitation. Another limitation of this study is the lack of long-term follow-up cardiac catheterization in all patients. Comparison of the intracardiac pressures with preoperative hemodynamics measured at cardiac catheterization is confounded by inherent differences between the 2 methods of measurement.

The study was unable to determine the relative importance of individual components of the LV rehabilitation procedure to the hemodynamic and clinical outcomes. The low mean LVOT gradient preoperatively in several patients undergoing the procedure suggests that restriction of blood flow through the LV was primarily due to the combination of mitral stenosis and endocardial restriction. Residual LV inflow and outflow gradients were encountered in many patients, despite surgical intervention, because of an increase in cardiac output or recalcitrant lesions. Improvement in ventricu- lar performance despite persistence of inflow and outflow obstruction may suggest a dominant role of EFE resection in the favorable outcome. Although aortic and mitral valve repairs without EFE resection may result in some hemodynamic improvement, EFE resection likely provides the additional hemodynamic benefit necessary to maintain biventricular circulation.

EFE is commonly associated with left heart obstructive lesions (secondary EFE), although it may also occur in structurally normal hearts (primary EFE) ${ }^{11,12}$ Mechanisms underlying the development of secondary EFE are unknown, although endocardial ischemia and decreased ventricular blood flow in utero have been proposed. In fetal animal models, LV unloading, but not LVOT obstruction, leads to development of EFE. ${ }^{13,14}$ Once EFE has formed, spontaneous regression is unlikely to occur, and surgical resection is the only means of relieving the endocardial restriction.

Recurrent or residual EFE was detected postoperatively by MRI in 3 patients. In these patients, the location of EFE was the LV surface of the interventricular septum. With a transmitral approach, access to the interventricular septum, particularly the basal aspect, is impaired by the anterior leaflet of the mitral valve. Similarly, visualization of this region through the aortic valve is limited by the small annular dimension and presence of subaortic obstruction. The impact of incomplete EFE resection in this region on ventricular systolic and diastolic function or long-term outcome is unclear. None of the patients in this series had recurrence of EFE within previous resection fields, suggesting that EFE does not redevelop in the postnatal myocardium. However, our experience with EFE resection in a different patient population (patients undergoing single-ventricle palliation and staged LV rehabilitation) has demonstrated that the fibrosis that occurs in the EFE resection bed is qualitatively different from true EFE. ${ }^{15}$

The mitral valve in patients with borderline left heart disease tends to share some common morphologic features. At the valvular level, mild annular hypoplasia, thickened leaflets, and commissural fusion may be present, but it is the subvalvar pathology that results in the most significant stenosis and abnormal flow dynamics. Fusion of the papillary muscles to the ventricular wall, foreshortened primary chordae, and hypertrophic accessory and secondary chordae limit excursion of the mitral leaflets and result in posteriorly oriented mitral orifice. By addressing the pathology at both the valvar and subvalvar levels, mitral valve rehabilitation promotes leaflet excursion and thereby redirects the inflow jet toward the apex rather than the posterior LV free wall. Development of mitral regurgitation in 1 patient early in this series necessitated mitral valve replacement, but significant mitral regurgitation has not occurred in our more recent experience with these techniques.

MRI has become our preferred imaging modality in patients with borderline left heart structures who are 
considered candidates for LV rehabilitation. MRI allows quantification of LV blood flow, which is useful in patients with an ASD and left-to-right atrial shunting. It is also more sensitive than echocardiography for the detection of EFE, although its sensitivity for recurrent EFE is unknown. ${ }^{16,17}$ Three-dimensional echocardiography allows surgical planning and has improved our understanding of the mechanisms underlying the aortic and mitral valve pathology in this population.

\section{CONCLUSIONS}

Primary LV rehabilitation procedure, when applied to patients with borderline left heart structures and severe EFE, allows maintenance of biventricular circulation with low operative mortality. Further follow-up is needed to establish whether the hemodynamic improvements will translate into long-term survival and improvement in quality of life.

\section{References}

1. Rhodes LA, Colan SD, Perry SB, Jonas RA, Sanders SP. Predictors of survival in neonates with critical aortic stenosis. Circulation. 1991;84:2325-35.

2. Schwartz ML, Gauvreau K, Geva T. Predictors of outcome of biventricular repair in infants with multiple left heart obstructive lesions. Circulation. 2001;104: 682-7.

3. Lofland GK, McCrindle BW, Williams WG, Blackstone EH, Tchervenkov CI, Sittiwangkul R, et al. Critical aortic stenosis in the neonate: a multi-institutional study of management, outcomes, and risk factors. Congenital Heart Surgeons Society. I Thorac Cardiovasc Surg. 2001;121:10-27.

4. Corno AF. Borderline left ventricle. Eur J Cardiothorac Surg. 2005;27:67-73.

5. Tchervenkov CI, Tahta SA, Jutras LC, Beland MJ. Biventricular repair in neonates with hypoplastic left heart complex. Ann Thorac Surg. 1998;66:1350-7.

6. Hickey EJ, Caldarone CA, Blackstone EH, Lofland GK, Yeh T Jr, Pizarro C, et al. Critical left ventricular outflow tract obstruction: the disproportionate impact of biventricular repair in borderline cases. J Thorac Cardiovasc Surg. 2007;134: 1429-37.

7. Han RK, Gurofsky RC, Lee KJ, Dipchand AI, Williams WG, Smallhorn JF, et al. Outcome and growth potential of left heart structures after neonatal intervention for aortic valve stenosis. J Am Coll Cardiol. 2007;50:2406-14.

8. Miyamoto T, Sinzobahamvya N, Wetter J, Kallenberg R, Brecher AM, Asfour B, et al. Twenty years experience of surgical aortic valvotomy for critical aortic stenosis in early infancy. Eur J Cardiothorac Surg. 2006;30:35-40.

9. Jalil JE, Janicki JS, Pick R, Abrahams C, Weber KT. Fibrosis-induced reduction of endomyocardium in the rat after isoproterenol treatment. Circ Res. 1989;65: 258-64.

10. Serraf A, Piot JD, Bonnet N, Lacour-Gayet F, Touchot A, Bruniaux J, et al. Biventricular repair approach in ducto-dependent neonates with hypoplastic but morphologically normal left ventricle. J Am Coll Cardiol. 1999;33:827-34.

11. Angelov A, Kulova A, Gurdevsky M. Endocardial fibroelastosis. Clinico-pathological study of 38 cases. Pathol Res Pract. 1984;178:384-8.

12. Sellers FJ, Keith JD, Manning JA. The diagnosis of primary endocardial fibroelastosis. Circulation. 1964;29:49-59.

13. Eghtesady P, Michelfelder E, Altaye M, Ballard E, Hirsh R, Beekman RH 3rd. Revisiting animal models of aortic stenosis in the early gestation fetus. Ann Thorac Surg. 2007;83:631-9.

14. Melnychenko I, Vasilyev NV, Scherr E, Freihs I, Poutias D, del Nido PJ. Hemodynamic mechanisms of endocardial fibroelastosis (EFE) in the developing rat heart (abstr). Circulation. 2008;118(Suppl 2):S908.

15. Emani SM, Tworetzky W, McElhinney DB, Schroeder B, Zurakowski D, Bacha E, et al. Staged left ventricular recruitment in patients with hypoplastic left heart disease and borderline left ventricle (abstr). Circulation. 2008; 118(Suppl 2):S750-1.

16. Tworetzky W, del Nido PJ, Powell AJ, Marshall AC, Lock JE, Geva T. Usefulness of magnetic resonance imaging of left ventricular endocardial fibroelastosis in infants after fetal intervention for aortic valve stenosis. Am J Cardiol. 2005;96: 1568-70.

17. Stranzinger E, Ensing GJ, Hernandez RJ. MR findings of endocardial fibroelastosis in children. Pediatr Radiol. 2008;38:292-6.

\section{Discussion}

Dr Frank Hanley (Stanford, Calif). Our experience at Lucille Packard Children's Hospital is similar in that we have grappled with this EFE problem as well. Our patients fall into 2 categories. One category is similar to yours in this study, that is, non-duct-dependent, slightly older children who have been managed interventionally or surgically for LVOT obstruction, who then don't do very well. We have 5 patients in this group.

Addressing your point about teasing out the different components of the repair, EFE resection, MV valve repair, and LVOT revision, to determine which one is doing the trick, we have $1 \mathrm{pa}-$ tient who is approximately 1.5 years old and had a coarct repair and aortic valve balloon dilation at another institution, with very good results on both. This patient had a $15 \mathrm{~mm} \mathrm{Hg} \mathrm{LVOT} \mathrm{gradient} \mathrm{and}$ only very mild mitral stenosis and mitral regurgitation combined, but was failing, and at catheterization had an LV end-diastolic pressure of $25 \mathrm{~mm} \mathrm{Hg}$ and pulmonary hypertension. So, this patient had only EFE resection, with no mitral or aortic procedure. A year later, he had a left atrial pressure of $9 \mathrm{~mm} \mathrm{Hg}$. So I think there is at least some early evidence that it really is the EFE resection that is effective, not just that we're doing something superfluous along with the valve procedures.

We also had 1 patient with a reduced ejection fraction of $40 \%$ late after EFE resection, although at catheterization the left atrial pressure was down from 25 to $12 \mathrm{~mm} \mathrm{Hg}$. This is of concern.

The other category of our patients with EFE, the one that you were kind enough to cite, is the neonatal duct-dependent patients who underwent operation with EFE resection, Ross-Konno, Norwood-type arch reconstruction, and sometimes mitral valve work. There are 9 of these patients.

I took the opportunity to apply the "univentricular repair survival advantage score," which you cited and applied to your patient group, to several of these neonatal patients with Ross-Konno EFE. Their survival scores ranged from +53 to +85 , much higher than the score in the older non-duct-dependent patients, and so a very, very different patient population.

With your group's interest in staging the neonatal duct-dependent patients and our interest in performing a primary Ross-Konno in them, it is clear that the neonates are managed differently than the older non-duct-dependent patients. Do you think we are at the point now where we need to expand the definition of borderline left heart disease, breaking them up into maybe 2 or 3 different subcategories within that designation, because there are distinctly different treatment approaches for these various patients?

Dr Emani. There are several approaches to the patient with a borderline left heart and an LV that is salvageable. We have typically considered patients to be candidates for the primary LV rehabilitation if we have been able to achieve satisfactory function of the aortic valve and biventricular circulation for a period of time. Patients with severe hypoplasia of multiple left-sided structures, Z-scores between -6 and -3 , typically require single-ventricle staged LV rehabilitation. This latter group is similar to your cohort of patients with UVR-SA scores greater than 50 . 
In patients undergoing staged LV rehabilitation, one interesting finding is that we have been able to rehabilitate even the most severely stenotic aortic valves such that only 2 of 9 patients have required the Ross procedure, suggesting that there is growth potential of the left-sided structures. It is not obvious whether the neonatal Ross-Konno or staged LV rehabilitation is superior in the patients with severe hypoplasia.

I think we need to make the distinction between these patients and patients with EFE and a borderline left heart whom you might be able to manage for a period of time with balloon dilations of the aortic valve and coarctation repair, but who eventually develop symptoms of congestive heart failure and right ventricular hypertension. In these patients, clinical deterioration is our cue to proceed with primary LV rehabilitation.

Dr Hanley. I take it you would tend to agree, then, that maybe we need to have borderline category 1 , borderline category 2 , maybe even a 3 , because we are handling these patients within borderline left heart differently.

Dr Emani. I think a major factor that helps us predict which patients with EFE might require staged versus the primary rehabilitation relates to the sizes of the aortic valve, mitral valve, and LV. I think the ventricles diminish in size compared with the body surface area if no attempts are made to rehabilitate the left heart in infancy. So there is some urgency to make this distinction early in infancy and not wait until they're older.

Dr Hanley. A very nice practical distinction is whether they are duct-dependent or not, which correlates closely with the aortic and mitral valves.

Dr Emani. I agree.

Dr Hanley. Now, a couple of more focused questions. You catheterized, I think, 5 of these patients both before and after surgery. It is encouraging to see the left atrial pressures come down; there is no question about that. Did you take the opportunity, and this again concerns your comment about the mitral and aortic valve gradients not changing statistically, although you did significant surgical work on it, to document the cardiac index to see if it went up after surgery?

Dr Emani. In the 5 patients who had catheterization, there was an apparent increase in cardiac output. However, I think that the cardiac index measured by the Fick method at catheterization is somewhat subject to loading conditions and assumptions about oxygen consumption. We frequently find that by the time they got to the hemodynamics there were a lot of other inotropic and fluid manipulations, and so we have not placed much value on this measurement; but statistically speaking, there was a difference in cardiac index before and after. We're trying to come up with more load-independent measures of function to get a feel for whether this is real or not.

Dr Hanley. The third question relates to what I perceive as a curious part of the management plan, that is, leaving the ASD open in some of the patients in your series. We all leave ASDs open in borderline right hearts, where you want to reduce the right atrial pressure and liver pressure, and so forth; but we all know that the downside to that is less pulmonary blood flow, which is not obligatory, so it's fine.

With borderline left heart disease, the physiologic argument is that you hurt the patient by leaving the ASD open, rather than help. You might lower left atrial pressure, but the downside of that is less loading conditions for the LV and less cardiac output. The left side of the circulation doesn't tolerate having a cardiac output of 0.7 . So I'm curious about the thinking that went into that part of the decision making.

Dr Emani. Most of that comes from our experience with the staged LV rehabilitation. We have had patients in whom a certain stage is achieved after an EFE resection and mitral and aortic valve work, and we take them to the catheterization laboratory to balloon occlude the ASD and measure left atrial pressures. In that series, there are some patients with elevated left atrial pressures that would be considered prohibitive. Initially, in the postoperative and primary LV rehabilitation period, we believe the LV compliance actually gets worse before it gets better. In many patients the left atrial pressure does increase within the first 24 hours. We keep all these patients intubated/paralyzed for 48 hours. We try to mitigate some of the fluctuations in left atrial pressure by doing that.

Dr James Tweddell (Milwaukee, Wis). How did you define borderline left heart for the purposes of this study?

Dr Emani. One or more of the left-sided structures having a Z-score between -3 and -1 , most often the aortic valve being the smallest structure. 